\title{
Horner's Syndrome and Trigeminal Nerve Palsy following Epidural Analgesia for Labor
}

\author{
MAJ James H. Lynch, MC, USA, MAJ Ryan J. Keneally, MC, USA, and \\ MAJ Thomas R. Hustead, MC, USA
}

Epidural analgesia is a widely used method of pain control in the labor and delivery setting but is not without risks. We present a case of Horner's syndrome and trigeminal nerve palsy as a rare complication of epidural analgesia in an obstetric patient. Although reported in few instances in the anesthesia literature, awareness among providers in obstetrics is critical because this could be the first sign of a high sympathetic blockade resulting in potential maternal-fetal morbidity. ( $\mathrm{J}$ Am Board Fam Med 2006; 19:521-3.)

\section{Case Report}

A healthy 25 -year-old woman, gravida 2 para 1, was admitted to the hospital for active labor at 39 weeks gestation. Her past medical history was remarkable only for occasional migraine headaches, and her prenatal course, including labs, had been unremarkable. During an uneventful first stage of labor, epidural anesthesia was requested. A lumbar epidural catheter was placed at the interspace between the third and fourth lumbar vertebrae using a midline approach and a loss of resistance to saline through a 17 -gauge Touhy needle. A test dose of 3 $\mathrm{mL}$ of $1.5 \%$ lidocaine with $5 \mu \mathrm{g}$ of epinephrine per milliliter was administered without appreciable evidence of either intravascular or intrathecal placement of the catheter. A bolus of $10 \mathrm{~mL}$ of $0.2 \%$ bupivacaine with $2 \mu \mathrm{g}$ of fentanyl per milliliter was administered over 10 minutes, and then an infusion of the same solution was started at $8 \mathrm{~mL}$ per hour. Approximately 20 minutes after epidural catheter placement, the patient complained that the left side of her face "felt funny." On evaluation by her family physician, the patient reported decreased sensa-

This article was externally peer-reviewed.

Submitted 30 January 2006; revised 23 May 2006; accepted 30 May 2006.

From the Department of Family Medicine (JHL, TRH); Department of Anesthesia (RJK), Tripler Army Medical Center, Hawaii (E-mail: james.h.lynch@us.army.mil)

Conflict of interest: none declared.

The views expressed in this manuscript are those of the authors and do not reflect the official policy or position of the Department of the Army, Department of Defense, or the U.S. Government.

Corresponding author: MAJ James H. Lynch, Tripler Army Medical Center, Department of Family Medicine, Hawaii (E-mail: james.h.lynch@us.army.mil). tion to light touch on the left cheek in the distribution of the maxillary branch of the trigeminal nerve and was observed to have miosis and ptosis on the left side. Pinprick demonstrated the level of analgesia at the fourth thoracic segment on the left and at the fifth thoracic segment on the right. The patient's grip strength was found to be normal, and she denied dyspnea. There were no other cranial nerve abnormalities or neurologic deficits appreciated.

Simultaneously, the patient's blood pressure dropped from $115 / 68 \mathrm{~mm} \mathrm{Hg}$ to a range of $90 \mathrm{~s} / 30 \mathrm{~s}$ $\mathrm{mm} \mathrm{Hg}$ for several minutes. After receiving $10 \mathrm{mg}$ of ephedrine $\mathrm{IV}$, her blood pressure returned to $110 \mathrm{~s} / 50 \mathrm{~s} \mathrm{~mm} \mathrm{Hg}$, but her neurologic symptoms persisted. During this period, fetal monitoring was uneventful without decelerations or bradycardia. Due to concerns for these neurologic findings, the epidural infusion was stopped, and labor allowed to progress. About 30 minutes after stopping the infusion, the patient's symptoms of facial numbness, ptosis, and miosis resolved.

Within the hour, the patient desired further pain control with epidural anesthesia. Therefore, she was repositioned, and an infusion of the same solution was started at $6 \mathrm{~mL}$ per hour without a bolus. This was followed by an uneventful progression of labor and vaginal delivery of a healthy male infant. No further signs or symptoms of Horner's syndrome or trigeminal nerve palsy were evident during the rest of this patient's labor, delivery, or postpartum period.

\section{Literature Search}

A PubMed search using terms "Horner's syndrome" or "trigeminal nerve palsy" and "epidural" 
limited to English language and humans found 29 case reports or series describing Horner's syndrome associated with epidural anesthesia. There are only 5 cases of trigeminal nerve palsy associated with epidural anesthesia since first being reported in 1985.

\section{Discussion}

Horner's syndrome has been described classically as unilateral ptosis, miosis, anhydrosis, and conjunctival injection and can be a rare side effect of epidural anesthesia. ${ }^{1}$ The exact incidence is unknown but appears greater among pregnant patients than the general population. ${ }^{2}$ In the labor and delivery setting the incidence of Horner's syndrome can be estimated at $0.4 \%$ to $2.5 \% .^{3} \mathrm{Al}$ though believed to be a benign, self-limited condition, there are reports of recurrent and persistent Horner's syndrome as well as concern for hemodynamic instability due to a high sympathetic block.

This constellation of findings in Horner's syndrome occurs with interruption of the sympathetic nerve fibers to the pupil, levator palpebrae, conjunctiva, and face. Several theories have been proposed, but the exact mechanism of Horner's syndrome associated with epidural anesthesia has not been agreed on. It is most plausible that these findings are consequences of a high sympathetic blockade from cephalad spread of local anesthetic. ${ }^{4,5}$ Horner's syndrome may be associated with a variety of conditions; however, when associated with epidural anesthesia it is believed to be caused by disruption of the oculosympathetic pathway where second order neurons exit the spinal cord (8th cervical and 1st thoracic nerves) on their path to the superior cervical ganglion. ${ }^{3}$

We cannot explain with certainty the exact mechanism of neurologic findings in the case of our patient, although given the temporal relationship, these findings certainly seem secondary to the anesthetic agent. We believe that the catheter was placed properly in the epidural space with the negative test dose probably precluding intrathecal or intravascular placement. The tract that the anesthetic agent followed is still unclear. Others who have tried to elucidate this mechanism speculate this response could be due to inadvertent partial dural puncture. ${ }^{4}$ However, the unilaterality of symptoms in our patient supports epidural spread due to the well described septation present in a large number of humans that divides the epidural space. Moreover, we feel that our patient's pregnant state contributed to the cephalad spread of the anesthetic. As has been described elsewhere, the parturient may be more prone to develop Horner's syndrome than the nonpregnant patient because of anatomic changes during pregnancy. The epidural space has less volume and reduced compliance due to epidural venous engorgement and increased intraabdominal pressure from the gravid uterus. Also, epidural pressure is transiently elevated during uterine contractions and can be significantly elevated if injection occurs during uterine contraction. ${ }^{6,7}$

Our case is particularly rare due to the concomitant trigeminal nerve palsy. There are only 5 reported cases in the literature of trigeminal nerve palsy similar to our patient. ${ }^{4,8-11}$ As with Horner's syndrome the exact mechanism is unclear but is probably due to high cephalad spread of local anesthetic in the epidural space, perhaps reaching the trigeminal nerve as it leaves its dural sheath, or from intrathecal spread affecting the spinal tract of the trigeminal nerve at its lowest part of the spinal cord. However, it is still unclear how only one branch of the trigeminal nerve appeared to be affected. Still, this cranial nerve involvement is thought to be a more serious consequence than Horner's syndrome alone, because this could signify further cephalad spread of the anesthetic agent. ${ }^{12}$ Similarly, other indications of a high blockade are upper extremity weakness or numbness, dyspnea, or, as with our patient, hypotension which can result in fetal bradycardia. ${ }^{4}$ Thus, while the neurologic findings associated with Horner's syndrome are typically quite harmless, they may signal an impending high sympathetic blockade or complete cardiopulmonary arrest.

Horner's syndrome associated with neuraxial blockade is generally temporary and benign. However, cases with serious complications such as fetal bradycardia associated with maternal hypotension have been reported. ${ }^{3}$ Most cases have been reported to resolve after stopping epidural infusion and are not associated with poor outcomes, but these symptoms may cause significant anxiety in the patient and family members, and among labor suite providers. A review of reported cases describes the mean time of onset of Horner's syndrome as 25 minutes after epidural injection (range a few minutes to 100 minutes), and the mean time of resolu- 
tion as 215 minutes (range a few minutes to 24 hours), depending on the agent used. There have also been cases of recurrent episodes of Horner's syndrome and at least one case of persistent Horner's syndrome that involved epidural analgesia that required surgical repair of ptosis at 6 months. The exact cause of this sustained Horner's syndrome is not clear. ${ }^{13,14}$ Another related case reported Horner's syndrome in a 32-year-old woman 2 weeks after a prolonged labor with spinal anesthesia. Her findings of miosis and ptosis were accompanied by head and neck pain, which was subsequently discovered to be due to internal carotid artery dissection. ${ }^{15}$ Although Horner's syndrome can be associated with epidural anesthesia in the labor and delivery setting, it should not be assumed that this is always the case, particularly if the clinical setting does not correlate as described above. Persistent Horner's syndrome should be worked up further to rule out other etiologies.

\section{Conclusion}

Horner's syndrome is a rare complication of epidural analgesia in laboring patients. Providers in obstetrics should be aware of this entity due to the potential for impending high sympathetic blockade. With careful evaluation and close monitoring, labor suite providers can take appropriate actions while reassuring the parturient of the usual benign and reversible nature of this condition without pursuing unnecessary diagnostic workups.

We thank the Family Medicine staff and residents of Tripler Army Medical Center for their thoughtful and critical review of this manuscript.

\section{References}

1. Kepes ER, Martinez LR, Pantuck E, Stark DCC. Horner's syndrome following caudal anesthesia. NY State J Med 1972;72:946-7.

2. Chandrasekhar S, Peterfreund RA. Horner's syn- drome following very low concentration bupivacaine infusion for labor epidural analgesia. J Clin Anesth 2003;15:217-9.

3. Biousse V, Guevara RA, Newmann NJ. Transient Horner's syndrome after lumbar epidural anesthesia. Neurology 1998;51:1473-5.

4. Narouze SN, Basali A, Mandel M, Tetzlaff JE. Horner's syndrome and trigeminal nerve palsy after lumbar epidural analgesia for labor and delivery. J Clin Anesth 2002;14:532-4.

5. Holzman RS. Unilateral Horner's syndrome and brachial plexus anesthesia during lumbar epidural blockade. J Clin Anesth 2002;14:464-6.

6. Schachner SM, Reynolds AC. Horner syndrome during lumbar epidural analgesia for obstetrics. Obstet Gynecol 1982;59:31S-2S.

7. Paw HG. Horner's syndrome following low-dose epidural infusion for labour: a cautionary tale. Eur J Anaesthesiol 1998;15:110-1.

8. Shigematsu T, Wang H, Nagano M. Trigeminal nerve palsy after lumbar epidural anesthesia. Anesth Analg 1985;64:653.

9. Sprung J, Haddox JD, Maitra-D'Cruze AM. Horner's syndrome and trigeminal nerve palsy following epidural anaesthesia for obstetrics. Can J Anaesth 1991;38:767-71.

10. Gazmuri RR, Ricke CA, Dagnino JA. Trigeminal nerve block as a complication of epidural anesthesia. Reg Anesth 1992;17:50-1.

11. Carrero EJ, Agusti M, Fabregas N, Valldeoriola F, Fernandez C. Unilateral trigeminal and facial nerve palsies associated with epidural analgesia in labour. Can J Anaesth 1998;45:893-7.

12. Wong SY, Lin CF, Lo LM, Peng TC, Chuah EC. Postpartum unilateral Horner's syndrome following lumbar epidural anesthesia after a Cesarean delivery. Chang Gung Med J 2004;27:624-8.

13. Yazbeck-Karam VG, Aouad MT, Baraka AS. Recurrent episodes of Horner's syndrome following epidural anesthesia in the obstetrical patients. Middle East J Anesthesiol 2001;16:257-63.

14. Hered RW, Cummings RJ, Helffrich R. Persistent Horner's syndrome after spinal fusion and epidural analgesia: a case report. Spine 1998;23:387-90.

15. Merrison AF, Lhatoo SD. Horner's syndrome postpartum. BJOG 2004;111:86-8. 